This is an electronic reprint of the original article. This reprint may differ from the original in pagination and typographic detail.

Author(s): Suhonen, Aku; Morgan, lan; Nauha, Elisa; Helttunen, Kaisa; Tuononen, Heikki; Nissinen, Maija

Title: $\quad$ Effect of a Rigid Sulfonamide Bond on Molecular Folding: A Case Study

Year: $\quad 2015$

Version:

Please cite the original version:

Suhonen, A., Morgan, I., Nauha, E., Helttunen, K., Tuononen, H., \& Nissinen, M. (2015). Effect of a Rigid Sulfonamide Bond on Molecular Folding: A Case Study. Crystal Growth and Design, 15(6), 2602-2608. https://doi.org/10.1021/acs.cgd.5b00424

All material supplied via JYX is protected by copyright and other intellectual property rights, and duplication or sale of all or part of any of the repository collections is not permitted, except that material may be duplicated by you for your research use or educational purposes in electronic or print form. You must obtain permission for any other use. Electronic or print copies may not be offered, whether for sale or otherwise to anyone who is not an authorised user. 


\title{
Effect of a Rigid Sulfonamide Bond on Molecular Folding: A
}

\section{Case Study}

Aku Suhonen, Ian S. Morgan, Elisa Nauha, Kaisa Helttunen, Heikki M. Tuononen and Maija

Nissinen*

University of Jyväskylä, Department of Chemistry, Nanoscience Center, P.O. BOX 35, 40014

University of Jyväskylä, Finland.

\begin{abstract}
A disulfonamide compound with bulky aromatic side chains was prepared and its properties as a potential building block for foldamers evaluated. Two different solvate crystal forms of the compound were identified and compared to the structures of an analogous oligoamide and related disulfonamides. The disulfonamide is unfolded in one of the solvates, whereas in the other one, a loosely folded conformer stabilized by an intramolecular hydrogen bond is found. Density functional calculations indicated that the loosely folded conformer is slightly more stable than its unfolded isomer. The calculations also identified a third, more tightly folded and more extensively hydrogen bonded conformer that is even lower in energy.
\end{abstract}

\section{Introduction}

The crystal form, the organization of molecules in a crystalline solid, depends on the conformational, functional and interaction properties of the compound, as well as, on the crystallization environment, such as temperature and solvent. On the other hand, the crystal form affects the physical properties of crystalline materials and provides information on conformational preferences and the interplay of intra- and intermolecular interactions and their 
role in formation of crystalline materials in varying conditions. ${ }^{1}$ Molecular conformation is especially important in the case of synthetic compounds that adopt structures mimicking those of biological molecules, such as peptides and proteins. These biomimetic molecular scaffolds, called foldamers, are composed of relatively simple repeating structural units and have, to some extent, predictable secondary structures stabilized by weak interactions between nonadjacent units. ${ }^{2,3}$ In addition to being artificial models for molecular folding, ${ }^{4}$ foldamers may express enzyme-like functions such as receptor properties and catalysis. ${ }^{5}$

The most common bond type used in the construction of foldamers is the amide bond. ${ }^{6,7}$ This is not only due to its analogy to peptide bonds but also because of its predictable hydrogen bonding properties. Another interesting, yet rarely used, bond type is the sulfonamide bond in which the sp ${ }^{2}$ carbon of an amide is replaced with an $\mathrm{sp}^{3}$ sulfur. ${ }^{8,9}$ This leads to differences in the preferred orientation of the $\mathrm{C}-\mathrm{N}$ and $\mathrm{S}-\mathrm{N}$ bonds and in the wideness of the $\mathrm{OXN}$ angles $\left(120^{\circ}\right.$ and $106^{\circ}$ for $\mathrm{X}=\mathrm{C}$ and $\mathrm{X}=\mathrm{S}$, respectively). Compared to amides, sulfonamides have different possibilities for intra- and intermolecular hydrogen bonding, ${ }^{10,11}$ which strongly affects their conformational properties and, hence, the propensity of sulfonamides to form polymorphs and co-crystals. ${ }^{12,13}$ In small peptides, the amide-to-sulfonamide replacement has been reported to lead to both striking differences as well as surprising similarities in the folding patterns. ${ }^{8,14}$

Co-crystallization studies of sulfonamide compounds have been conducted to improve their properties, such as solubility, and to explore their potential as building blocks for new molecular assemblies with improved pharmaceutical properties. ${ }^{15}$ Sulfonamides were the first clinically available antibacterial agents ${ }^{16}$ and they have been widely used in the design of drug candidates. ${ }^{17,18}$ Another potential use for sulfonamide compounds is (stereoselective) 
organocatalysis because of their capacity to form fairly weak hydrogen bonds and their increased acidity compared to the amide group. ${ }^{19,20}$

In our previous study, we focused on aromatic oligoamides as potential foldamers and studied their conformational properties, polymorphism and solvate formation. ${ }^{21,22}$ In order to investigate the effect of amide-to-sulfonamide replacement on molecular conformation and folding, we have now prepared a sulfonamide analogue (2) of one of the previously synthesized oligoamides (3). 21 The structural properties of the sulfonamide 2 were investigated in the solid state and in solution as well as by performing density functional theory (DFT) calculations. The results are compared and contrasted with the data of the oligoamide $\mathbf{3}$, as well as for other related disulfonamides described in the literature.

\section{Experimental}

\section{Materials and methods}

All starting materials were commercially available and used as such unless otherwise noted. Analytical grade solvents and Millipore water were used for crystallizations. NMR spectra were measured with a Bruker Avance DRX 500 spectrometer and the chemical shifts were calibrated to the residual proton and carbon resonances of the deuterated solvent. Melting points were measured in open capillaries using a Stuart Scientific SMP3 melting point apparatus and are uncorrected. ESI-TOF mass spectra were measured with a LCT Micromass spectrometer. Elemental analyses were done with a Vario EL III instrument.

\section{Syntheses}

All syntheses were carried out under $\mathrm{N}_{2}$ atmosphere. The glassware was dried at $120^{\circ} \mathrm{C}$ prior

to use. Dichloromethane was dried by distillation over $\mathrm{CaCl}_{2}$ and stored over Linde type $3 \AA$ 
molecular sieves under nitrogen gas. Compound $\mathbf{1}$ was prepared by a published method, ${ }^{21}$ which is a slight modification to an earlier literature procedure. ${ }^{23}$ Compound $\mathbf{2}$ was also prepared by a slightly modified literature procedure. ${ }^{24}$

\section{$N$-Benzoyl-2-aminoaniline 1}

O-phenylenediamine $(8.97 \mathrm{~g} ; 83.1 \mathrm{mmol})$ was dissolved in dry dichloromethane $(350 \mathrm{ml})$. Triethylamine $(3.0 \mathrm{ml} ; 21.6 \mathrm{mmol})$ was added and the solution was heated to reflux with stirring. Benzoyl chloride $(2.16 \mathrm{~g} ; 20.7 \mathrm{mmol})$ dissolved in dry dichloromethane $(200 \mathrm{ml})$ was added dropwise to the solution. The solution was allowed to reflux for two hours. The product was separated by column chromatography using a silica column and an ethyl acetate-hexane (1:1) mixture as the eluent. Recrystallization from ethyl acetate-hexane afforded the product as a white solid, yield. $3.57 \mathrm{~g}(81 \%)$. mp. $149-151{ }^{\circ} \mathrm{C} ;{ }^{1} \mathrm{H}$ NMR $\left(500 \mathrm{MHz}, \mathrm{DMSO}-d_{6}, 30{ }^{\circ} \mathrm{C}\right): \delta=$ $4.87(\mathrm{~s}, 2 \mathrm{H} ; \mathrm{i}), 6.60\left(\mathrm{td},{ }^{3} \mathrm{~J}_{\mathrm{HH}}=1.2 \mathrm{~Hz},{ }^{3} \mathrm{~J}_{\mathrm{HH}}=7.6 \mathrm{~Hz}, 1 \mathrm{H} ; \mathrm{g}\right), 6.79\left(\mathrm{dd},{ }^{3} \mathrm{~J}_{\mathrm{HH}}=1.3 \mathrm{~Hz},{ }^{3} \mathrm{~J}_{\mathrm{HH}}=8.1\right.$ $\mathrm{Hz}, 1 \mathrm{H} ; \mathrm{e}), 6.97\left(\mathrm{td},{ }^{3} \mathrm{~J}_{\mathrm{HH}}=1.2 \mathrm{~Hz},{ }^{3} \mathrm{~J}_{\mathrm{HH}}=7.6 \mathrm{~Hz}, 1 \mathrm{H} ; \mathrm{f}\right), 7.18\left(\mathrm{~d},{ }^{3} \mathrm{~J}_{\mathrm{HH}}=7.7 \mathrm{~Hz}, 1 \mathrm{H} ; \mathrm{d}\right), 7.51(\mathrm{t}$, $\left.{ }^{3} \mathrm{~J}_{\mathrm{HH}}=7.4 \mathrm{~Hz}, 2 \mathrm{H} ; \mathrm{b}\right), 7.55-7.60(\mathrm{~m}, 1 \mathrm{H} ; \mathrm{a}), 7.98\left(\mathrm{~d},{ }^{3} \mathrm{~J}_{\mathrm{HH}}=7.4 \mathrm{~Hz}, 2 \mathrm{H} ; \mathrm{c}\right), 9.63(\mathrm{~s}, 1 \mathrm{H} ; \mathrm{h}) \mathrm{ppm}$; ${ }^{13} \mathrm{C}$ NMR $\left(126 \mathrm{MHz}, \mathrm{DMSO}-d_{6}, 30{ }^{\circ} \mathrm{C}\right): \delta=116.1,116.2,123.3,126.4,127.6,128.2,131.2$, 134.6, 143.0, $165.2 \mathrm{ppm}$; MS (ESI-TOF) m/z calcd for $\mathrm{C}_{13} \mathrm{H}_{12} \mathrm{~N}_{2} \mathrm{O}, 212.25$, found 235.08 [M + $\mathrm{Na}]^{+}$; elemental analysis calcd (\%) for $\mathrm{C}_{13} \mathrm{H}_{12} \mathrm{~N}_{2} \mathrm{O}$ : C 73.6, H 5.7, $\mathrm{N} \mathrm{13.2;} \mathrm{found} \mathrm{C} \mathrm{73.8,} \mathrm{H} \mathrm{5.6,} \mathrm{N}$ 13.3 .

\section{$N^{1}, N^{3}$-bis(2-benzamidophenyl)benzene-1,3-disulfonamide 2}

$N$-benzoyl-2-aminoaniline 1 (0.471 g; $2.22 \mathrm{mmol})$ was dissolved in pyridine $(15 \mathrm{ml})$. The solution was stirred and benzene-1,3-disulfonyl chloride $(0.307 \mathrm{~g} ; 1.11 \mathrm{mmol})$ dissolved in pyridine $(15 \mathrm{ml})$ was added dropwise to the mixture. The solution was refluxed for two hours after which the stirring was continued for 24 hours. $2 \mathrm{M} \mathrm{HCl}$ was added to the solution and a 
precipitate formed; if the precipitate did not form, $6 \mathrm{M} \mathrm{HCl}$ solution was added. The precipitate was filtered and washed with water. The precipitate was then dissolved in absolute ethanol and concentrated. The concentrated product was dissolved in ethanol and precipitated as a pink solid by adding water and dried in vacuum, yield $0.37 \mathrm{~g}(63 \%)$. mp. $213-216{ }^{\circ} \mathrm{C} ;{ }^{1} \mathrm{H}$ NMR $(500$ MHz, DMSO- $\left.d_{6}, 30^{\circ} \mathrm{C}\right): \delta=6.90\left(\mathrm{dd}, 2 \mathrm{H},{ }^{3} \mathrm{~J}_{\mathrm{HH}}=1.5 \mathrm{~Hz},{ }^{3} \mathrm{~J}_{\mathrm{HH}}=8.1 \mathrm{~Hz}\right), 7.07\left(\mathrm{td}, 2 \mathrm{H},{ }^{3} \mathrm{~J}_{\mathrm{HH}}=1.4\right.$ $\left.\mathrm{Hz},{ }^{3} \mathrm{~J}_{\mathrm{HH}}=7.8 \mathrm{~Hz}\right), 7.26\left(\mathrm{td}, 2 \mathrm{H},{ }^{3} \mathrm{~J}_{\mathrm{HH}}=1.4 \mathrm{~Hz},{ }^{3} \mathrm{~J}_{\mathrm{HH}}=7.8 \mathrm{~Hz}\right), 7.52-7.57(\mathrm{~m}, 5 \mathrm{H}), 7.62(\mathrm{tt}, 2 \mathrm{H}$, $\left.{ }^{3} \mathrm{~J}_{\mathrm{HH}}=1.5 \mathrm{~Hz},{ }^{3} \mathrm{~J}_{\mathrm{HH}}=7.3 \mathrm{~Hz}\right), 7.76-7.80(\mathrm{~m}, 4 \mathrm{H}), 7.81-7.84(\mathrm{~m}, 4 \mathrm{H}), 8.00\left(\mathrm{st}, 1 \mathrm{H},{ }^{3} \mathrm{~J}_{\mathrm{HH}}=1.8\right.$ $\mathrm{Hz}), 9.54$ (s, 2H), 9.84 (s, 2H) ppm.; ${ }^{13} \mathrm{C}$ NMR (126 MHz, DMSO-d $\left.6,30{ }^{\circ} \mathrm{C}\right): \delta 124.7$ (d), 125.3 (g), 126.2 (e), 127.0 (f), 127.3 (c), 127.8 (e'), 128.5 (b), 130.6 (j), 130.8 (h), 131.8 (a). 133.2 (d'), $134.0\left(c^{\prime}\right), 140.3(j), 165.1\left(k^{\prime}\right)$; HRMS (ESI+) $m / z[M+N a]^{+}$calcd for $\left[\mathrm{C}_{32} \mathrm{H}_{26} \mathrm{~N}_{4} \mathrm{O}_{6} \mathrm{~S}_{2} \mathrm{Na}\right]$ 649.1191, found $649.1186, \Delta=-0.8 \mathrm{ppm}$.

\section{Crystallizations}

X-ray quality crystals were obtained from ethyl acetate-hexane diffusion (EtOAc-Hex) and evaporation of acetonitrile (MeCN), 1,2-dichloroethane (DCE) or tetrahydrofuran (THF) solutions. However, only preliminary structures could be obtained for the $\mathrm{MeCN}$ and THF solvates (see ESI for details). In all evaporation crystallizations, $20 \mathrm{mg}$ of compound 2 was dissolved in 2-6 $\mathrm{ml}$ of the solvent. Heating and stirring were used to help the dissolving process. After the compound had fully dissolved, slow evaporation of the solvent was allowed at room temperature. In diffusion crystallization, $2 \mathrm{mg}$ of compound 2 was dissolved in $0.5 \mathrm{ml}$ of ethyl acetate and $2 \mathrm{ml}$ of hexane was used as an antisolvent in a closed container. The sample was left to crystallize at room temperature. 


\section{X-ray crystallography}

Single crystal X-ray diffraction data was collected with a Bruker Nonius KappaCCD diffractometer at $173 \mathrm{~K}$ using a Bruker AXS APEX II CCD-detector and graphitemonochromated $\mathrm{CuK} \alpha$-radiation $(\lambda=1.54178 \AA$ ). The structures were solved with direct methods and refined using Fourier techniques with the SHELX-97 software package. ${ }^{25}$ Absorption correction was performed with Denzo-SMN 1997. ${ }^{26}$ All hydrogen atoms were placed to their idealized positions except for the $\mathrm{N}-\mathrm{H}$ hydrogens that were located from the electron density map and included in the structure factor calculations. Electron density of severely disordered solvent molecules in the EtOAc solvate structure was removed with the SQUEEZE ${ }^{27}$ routine included in the PLATON ${ }^{28}$ program in the WinGX package. ${ }^{29}$ Full details of the crystallographic data and refinement are presented in Table 1 and in the ESI. Graph set symbols for hydrogen bonding were assigned and used to compare the bonding between the different crystal structures. ${ }^{30,31}$

\section{Computational details}

All calculations were performed with the Gaussian $09^{32}$ program package using the $\omega$ B97XD density functional ${ }^{33}$ and Ahlrichs' def2-TZVP basis sets. ${ }^{34}$ The chosen density functional includes an empirical dispersion correction term and it can better treat hydrogen bonding and van der Waals interactions than many conventional density functionals such as B3LYP. The initial geometries of conformers of $\mathbf{2}$ were taken directly from the single crystal X-ray diffraction data. The global minimum conformation, 2III, was obtained via potential energy surface scans in which the torsion angles of the sulfonamide substituents were systematically varied keeping the other geometry parameters frozen. These scans were performed using a lower level basis set. The minima found were subjected to subsequent geometry optimizations using the same functional 
and basis set as used for 2I and 2II. Gas phase geometry optimizations were performed for all systems and the nature of the located minima confirmed by performing a full vibrational analysis. In addition to gas phase calculations, a polarized continuum solvent model (IEFPCM) ${ }^{35}$ was used in order to determine if the bulk properties of the solvents (EtOAc and DCE) had significant influence on the energetic preference of different conformers of $\mathbf{2}$. The energy values reported in the text are enthalpy differences obtained at $298 \mathrm{~K}$ and $1 \mathrm{~atm}$.

Table 1. Crystallographic Data for Solvate 2I (EtOAc) and Solvate 2II (DCE).

\begin{tabular}{|c|c|c|}
\hline & Solvate 2I (EtOAc) & Solvate 2II (DCE) \\
\hline Formula & $\mathrm{C}_{32} \mathrm{H}_{26} \mathrm{~N}_{4} \mathrm{O}_{6} \mathrm{~S}_{2}$ & $\mathrm{C}_{32} \mathrm{H}_{26} \mathrm{~N}_{4} \mathrm{O}_{6} \mathrm{~S}_{2} \cdot \mathrm{C}_{2} \mathrm{H}_{4} \mathrm{Cl}_{2}$ \\
\hline $\mathrm{M} / \mathrm{gmol}^{-1}$ & 626.69 & 725.64 \\
\hline Crystal system & monoclinic & monoclinic \\
\hline Space group & $C 2 / c$ & $P 2{ }_{1} / c$ \\
\hline$a / \AA$ & $24.758(2)$ & $13.1334(3)$ \\
\hline$b / \AA$ & $6.9874(5)$ & $22.7870(6)$ \\
\hline$c / \AA ̊$ & $21.0600(12)$ & $11.6864(4)$ \\
\hline$\beta /^{\circ}$ & $106.985(3)$ & $104.874(10)$ \\
\hline$V / \AA^{3}$ & $3484.3(4)$ & $3380.2(2)$ \\
\hline$Z$ & 4 & 4 \\
\hline$\rho_{\text {cald }} / \mathrm{g} \mathrm{cm}^{-3}$ & 1.195 & 1.426 \\
\hline Meas. reflns & 4899 & 11132 \\
\hline Indep. reflns & 2984 & 5889 \\
\hline$R_{\text {int }}$ & 0.0449 & 0.0427 \\
\hline$R_{1}[I>2 \sigma(I)]$ & 0.0469 & 0.0449 \\
\hline$w R_{2}[I>2 \sigma(I)]$ & 0.1216 & 0.1104 \\
\hline GooF & 1.050 & 1.015 \\
\hline
\end{tabular}




\section{Results and Discussion}

The $N^{1}, N^{3}$-bis(2-benzamidophenyl)benzene-1,3-disulfonamide (2) was synthesized in good yield by a nucleophilic substitution reaction between $N$-benzoyl-2-aminoaniline (1) and benzene1,3-disulfonyl chloride (Scheme 1). The product was characterized by ${ }^{1} \mathrm{H}$ and ${ }^{13} \mathrm{C}$ NMR spectroscopy including 2D techniques (COSY, HMQC, HMBC and NOESY; see ESI for details).

Scheme 1. Synthesis of disulfonamide 2.

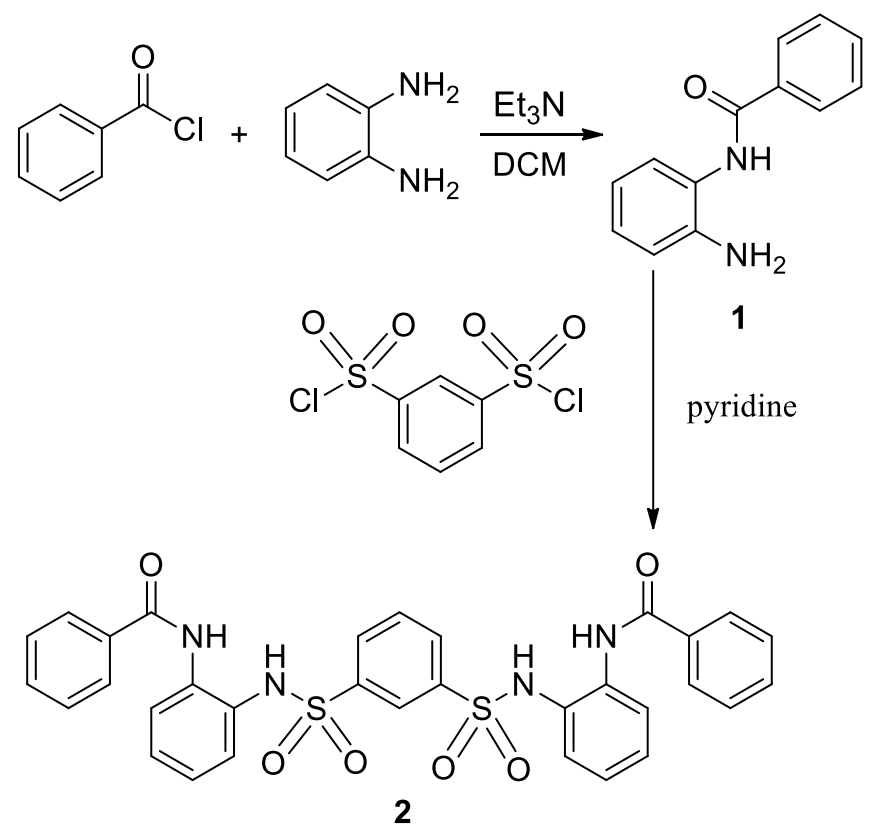

The ${ }^{1} \mathrm{H}$ NMR spectra of $\mathbf{2}$ in DMSO- $d_{6}$ and acetone- $d_{6}$ at room temperature are consistent with a symmetric structure for the molecular backbone, which indicates either the presence of a single preferred conformer with $C_{2}$-symmetry axis or multiple conformers undergoing rapid exchange in NMR timescale. Variable temperature ${ }^{1} \mathrm{H}$ NMR measurements in acetone- $d_{6}$ showed no significant splitting of the proton signals when the temperature was gradually lowered to $-80^{\circ} \mathrm{C}$, 
which confirmed that a rapid exchange process is unlikely. A NOESY NMR spectra of 2 in acetone- $d_{6}$ indicated NOEs between the protons of the terminal phenyl substituents and the hydrogen atoms of the sulfonamide groups, but this information was inconclusive for a detailed conformational determination.

\section{Crystallographic studies}

Compound $\mathbf{2}$ was crystallized as two solvates, the ethyl acetate solvate (EtOAc, solvate 2I) and the dichloroethane solvate (DCE, solvate 2II), which differ by the conformation of 2 (Figure 1). Two lower quality preliminary structures were also obtained: an acetonitrile $(\mathrm{MeCN})$ solvate that is isomorphous with the EtOAc solvate 2I and a tetrahydrofuran (THF) solvate that is isomorphous with the DCE solvate 2II (see ESI for details). In addition, powder diffraction data collected for the samples obtained from ethanol and methanol crystallizations of $\mathbf{2}$ suggest the existence of a third currently unknown crystal form, since the diffraction pattern bears very little resemblance to the patterns calculated from the single crystal X-ray structures of solvates $\mathbf{2 I}$ and 2II (see ESI for details).

In both conformers, the $\mathrm{S}-\mathrm{N}$ bonds are roughly perpendicular to the plane of the central aromatic ring, which is typical to sulfonamides. In the structure of solvate $\mathbf{2 I}$, the conformation of $\mathbf{2}$ is unfolded and symmetrical with the $\mathrm{S}-\mathrm{N}$ bonds oriented on opposite sides of the central ring, whereas the conformation of $\mathbf{2}$ in solvate $\mathbf{2 I I}$ is loosely folded and asymmetric with the $\mathrm{S}-\mathrm{N}$ bonds on the same side of the central ring (Figure 1). In the analogous oligoamide $\mathbf{3}$, the $\mathrm{C}-\mathrm{N}$ bonds are on the same plane with the central aromatic ring, and a loosely folded conformer is stabilized by two intramolecular hydrogen bonds between neighboring amide groups (Figure 2). ${ }^{21}$ 

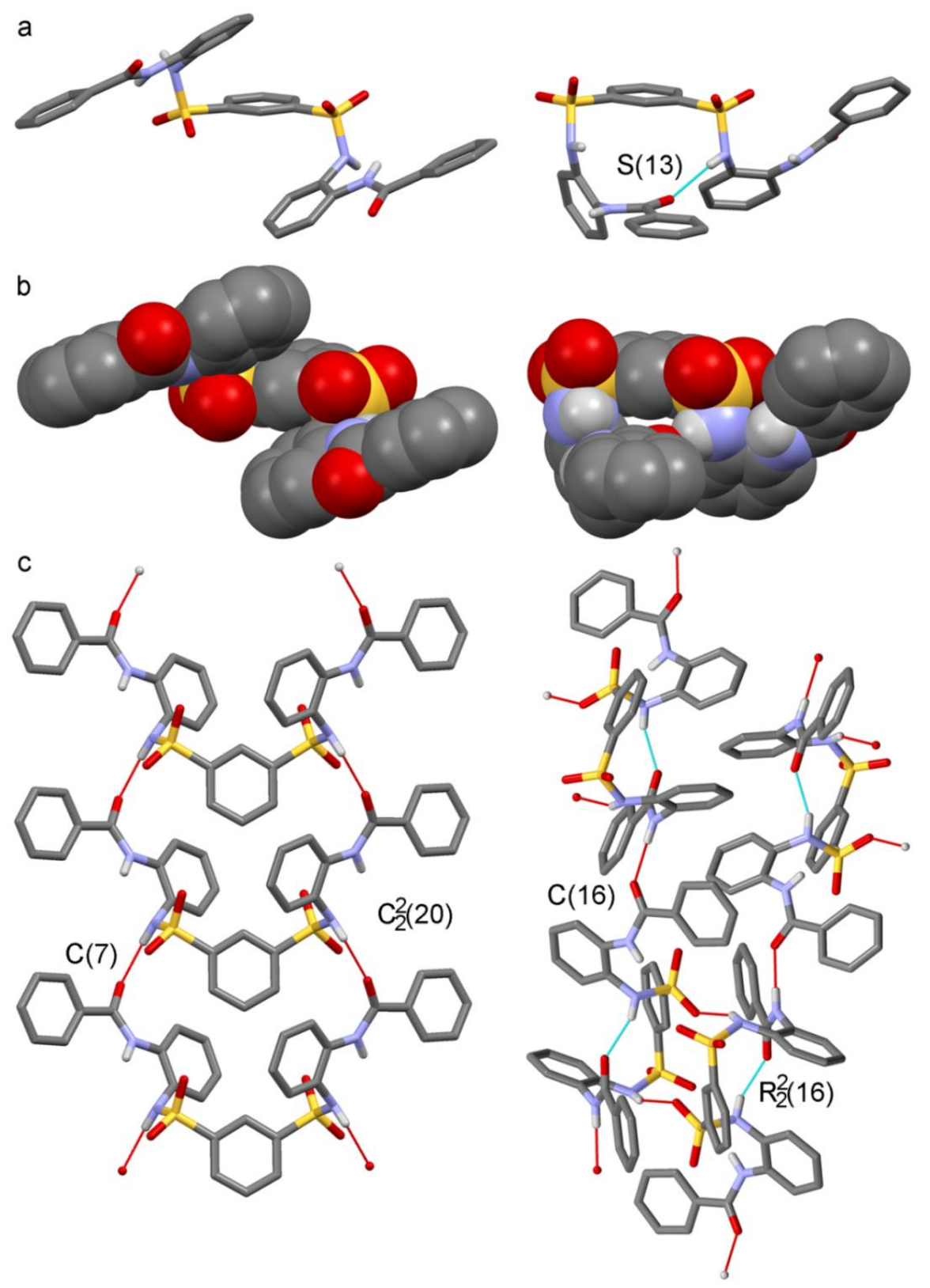

Figure 1. Two conformers of the disulfonamide compound 2 crystallized from EtOAc (left, solvate 2I) and DCE (right, solvate 2II) shown as stick (a) and space fill (b) depictions. The crystal packing highlighting intermolecular hydrogen bonding (c). Disordered solvent molecules and non-amide/sulfonamide hydrogen atoms have been removed for clarity. 

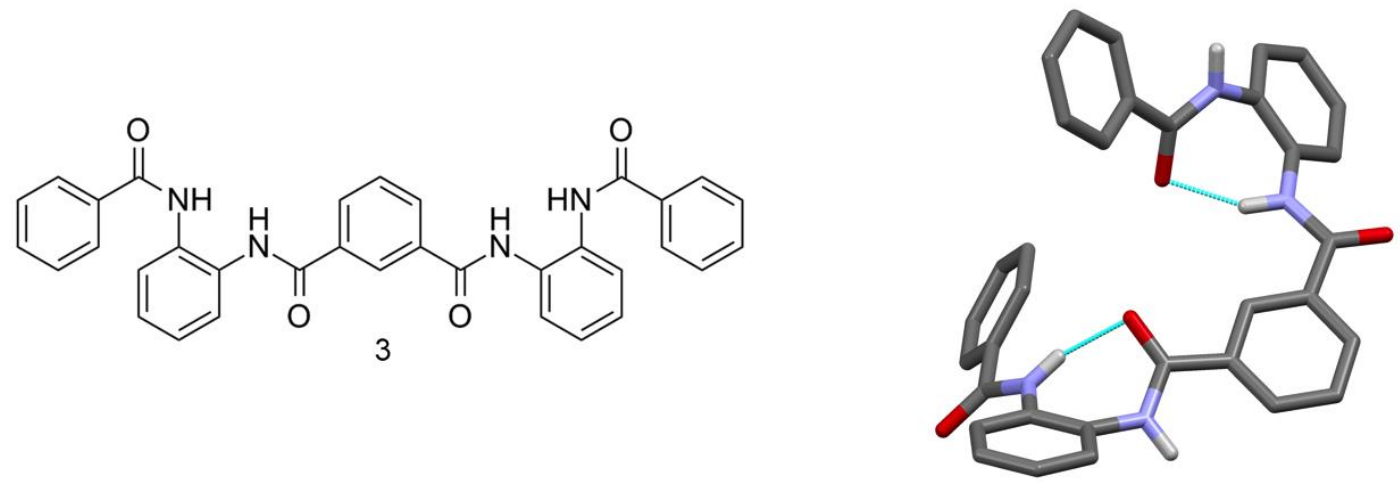

Figure 2. The loosely folded conformation of oligoamide $3 .^{21}$ Non-amide hydrogen atoms have been removed for clarity.

The conformer of solvate $\mathbf{2 I}$ is stabilized by two weak intramolecular amide-to-sulfonamide

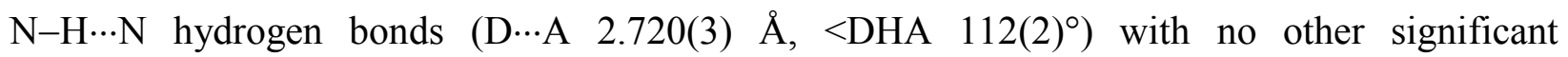
intramolecular interactions present. Thus, the conformation in solvate 2I appears to be mostly influenced by intermolecular interactions and packing effects instead of strong intramolecular interactions. Accordingly, the disulfonamide 2 forms two intermolecular $\mathrm{N}-\mathrm{H} \cdots \mathrm{O}=\mathrm{C}$ hydrogen

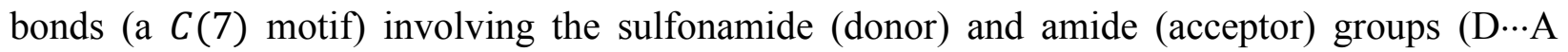
2.793(3) $\AA,<$ DHA $\left.171(3)^{\circ}\right)$. The hydrogen bonding connects the molecules into chains along the crystallographic $b$-axis, therefore giving rise to a double chain pattern $\left(C_{2}^{2}(20)\right.$ motif) with headto-tail arrangement of molecules in the chains (Figure 1). The individual chains exhibit offset $\pi-\pi$ stacking interactions between the outermost phenyl rings of neighboring molecules of $\mathbf{2}$ (see ESI for details). The packing of 2 into parallel chains creates channels, which contain severely disordered solvent molecules. This kind of disorder is expected as there are no restricting interactions between the solvent and the channel walls. 
The conformation of $\mathbf{2}$ in solvate 2 II reveals an intramolecular $\mathrm{N}-\mathrm{H} \cdots \mathrm{O}=\mathrm{C}$ hydrogen bond

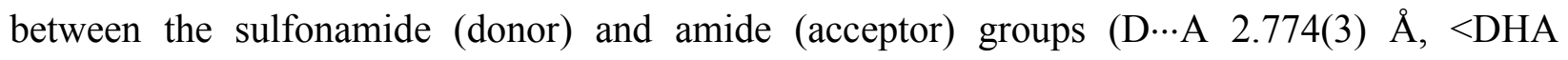
$\left.158(3)^{\circ}\right)$ that gives 2 a folded conformation $(S(13)$ motif). The crystal packing is dominated by

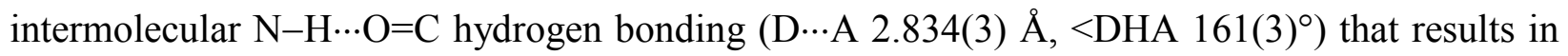
the formation of molecular chains along the crystallographic $b$-axis $(C(16)$ motif). The chains are further interconnected to sheet-like assemblies by two weak $\mathrm{N}-\mathrm{H} \cdots \mathrm{O}=\mathrm{S}$ hydrogen bonds

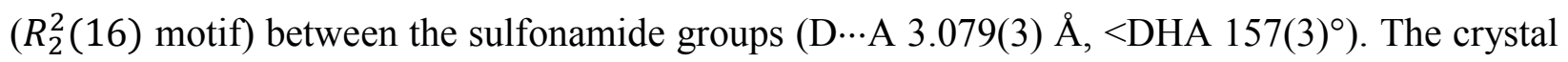
packing of solvate 2II also reveals $\pi-\pi$ stacking interactions between the $R_{2}^{2}(16)$ bonded molecular pairs (see ESI for details). The disordered DCE molecules are located in the solvent accessible voids between molecules of $\mathbf{2}$.

The primary hydrogen bonding networks in solvates $\mathbf{2 I}$ and $\mathbf{2 I I}$ can be rationalized with the tendency of $\mathbf{2}$ to maximize interactions involving the amide carbonyls, since the amide carbonyl oxygen is known to be a better hydrogen bond acceptor than the sulfonyl oxygen. ${ }^{11}$ Consequently, the sulfonyl groups act as hydrogen bond acceptors only between the molecular chains in the solvate 2 II structure. This also means that there are amide and sulfonamide NH groups in both conformers of $\mathbf{2}$ that do not take part in the primary hydrogen bonding network.

The reasons why different solvents and crystallization procedures lead to two different conformers of $\mathbf{2}$ are not obvious. The environmental conditions (temperature, moisture and crystallization vessels) were kept as identical as possible for all experiments and there are no clear trends in the results in relation to the physical and chemical properties of the solvents used. It can be argued that DCE is a poor hydrogen bond acceptor compared to an amide carbonyl, and therefore compound $\mathbf{2}$ should form intramolecular hydrogen bonds more willingly (solvate 2II) than when better hydrogen bond acceptors, such as EtOAc or $\mathrm{MeCN}$, are used as solvents 
(solvate 2I). However, the conformation of $\mathbf{2}$ in the THF solvate contradicts with this interpretation as the hydrogen bond acceptor properties of THF are more in line with those of EtOAc and MeCN than with DCE, but still a folded, isomorphous conformer to $\mathbf{2 I}$, was nevertheless obtained. ${ }^{36}$ Therefore, the likely explanation for two different conformers of 2 is that conformers are very close in energy and the interplay of inter- and intramolecular hydrogen bonding along with intramolecular steric hindrance caused by the bulky phenyl rings directs the organization of molecules to two different structures during crystal nucleation.

\section{Computational studies}

In order to obtain more insight into the conformational features of $\mathbf{2}$, its potential energy surface was analyzed with DFT by optimizing the structures of the two conformers observed in the solid state at the $\omega \mathrm{B} 97 \mathrm{XD} / \mathrm{def} 2-\mathrm{TZVPP}$ level of theory.

The optimized structure of $\mathbf{2 I}$ is similar to the conformer in solvate $\mathbf{2 I}$ with major changes only in the hydrogen bonding network. The weak $\mathrm{N}-\mathrm{H} \cdots \mathrm{N}$ bonds observed in the crystal structure are

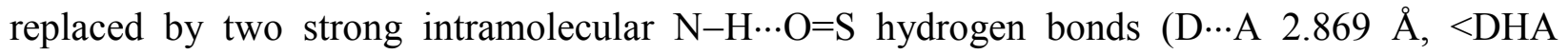
$154.1^{\circ}$ ) that result in a significantly more compact molecular geometry (Figures 3a and 4a). This is expected as the orientation of the amide groups in the model system, a single molecule of $\mathbf{2}$, is not fixed by intermolecular $\mathrm{N}-\mathrm{H} \cdots \mathrm{O}=\mathrm{C}$ hydrogen bonds whose formation is preferred in the solid state.

Unlike the structure $\mathbf{2 I}$, the optimized geometry of $\mathbf{2 I I}$ is practically identical to the conformer in solvate 2II (Figures $3 \mathrm{~b}$ and $4 \mathrm{~b}$ ). The calculations reproduce well the intramolecular

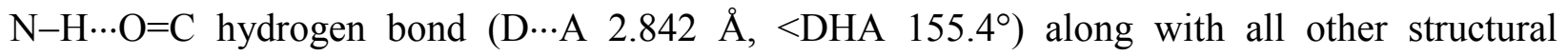
features of the molecular backbone. Only the torsional angles of the terminal phenyl groups are 
different as the rotation of these groups is the most affected by crystal packing which is not taken into account in calculations.

The computational results show that the conformer in solvate 2I does not retain its crystal structure geometry without explicitly taking into account intermolecular interactions. Thus, the strong hydrogen bonding between neighboring molecules in the solid state plays a role in determining the conformation of the molecule. This was tested computationally by optimizing a dimeric pair of $\mathbf{2 I}$ in the crystal structure geometry, in which case the intermolecular $\mathrm{N}-\mathrm{H} \cdots \mathrm{O}=\mathrm{C}$ hydrogen bonds kept the "tailing" molecule rather rigidly in place, whereas the geometry of the "heading" molecule changed from an open to a more compact form due to the formation of intramolecular $\mathrm{N}-\mathrm{H} \cdots \mathrm{O}=\mathrm{S}$ interactions (Figure $3 \mathrm{~d}$ and $4 \mathrm{c}$ ). Since the conformer of solvate 2II was accurately reproduced even with the simplest possible model system, it seems that the folded conformer of $\mathbf{2}$, once formed, can effectively guide the construction of a strong hydrogen bonding network around it. 


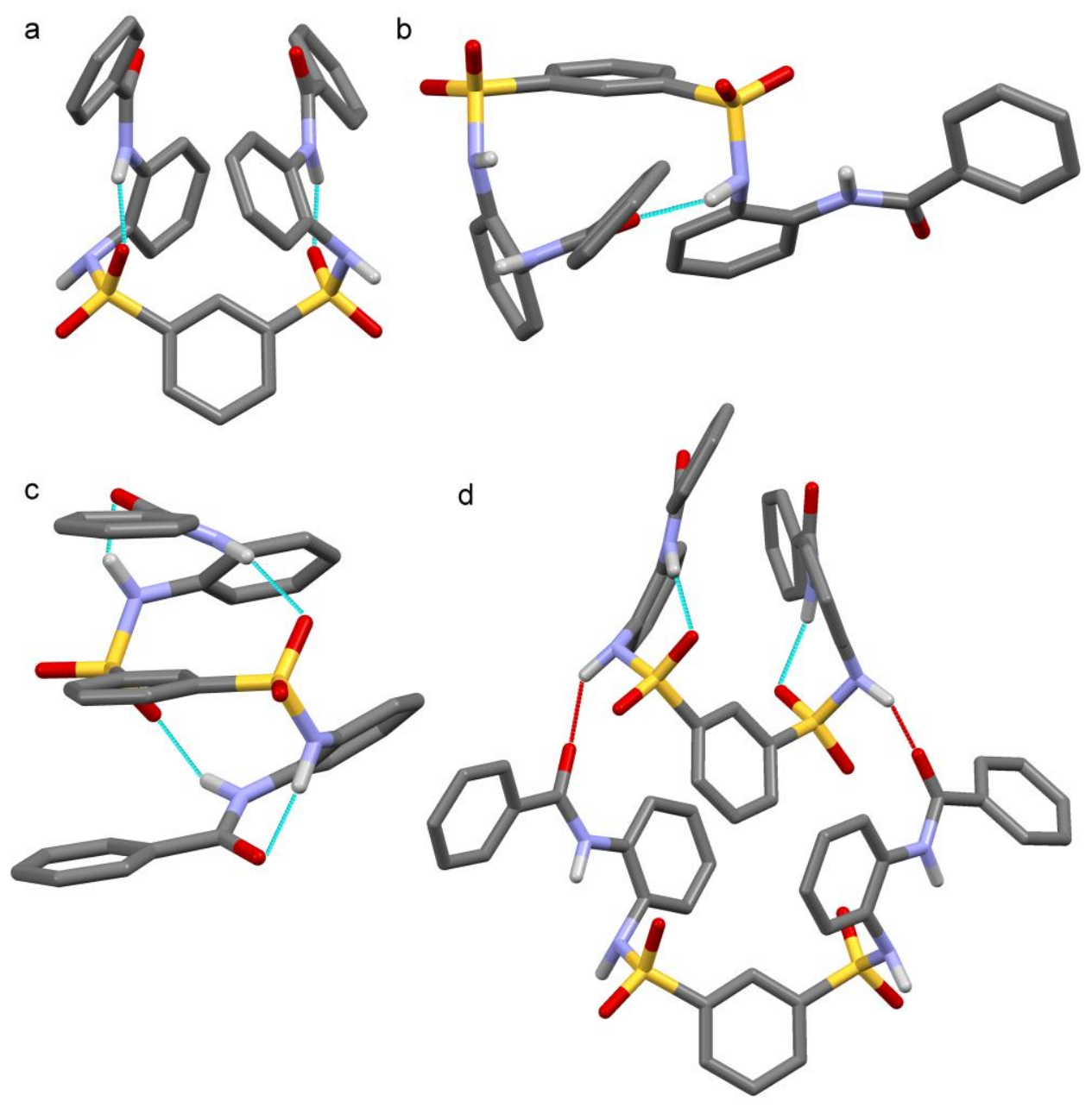

Figure 3. Optimized ( $\omega B 97 \mathrm{XD} / \mathrm{def} 2-\mathrm{TZVPP})$ structures of $\mathbf{2 I}(\mathrm{a}), \mathbf{2 I I}$ (b) and 2III (c) and a dimeric pair of 2I (d). Non-amide/sulfonamide hydrogen atoms have been removed for clarity 

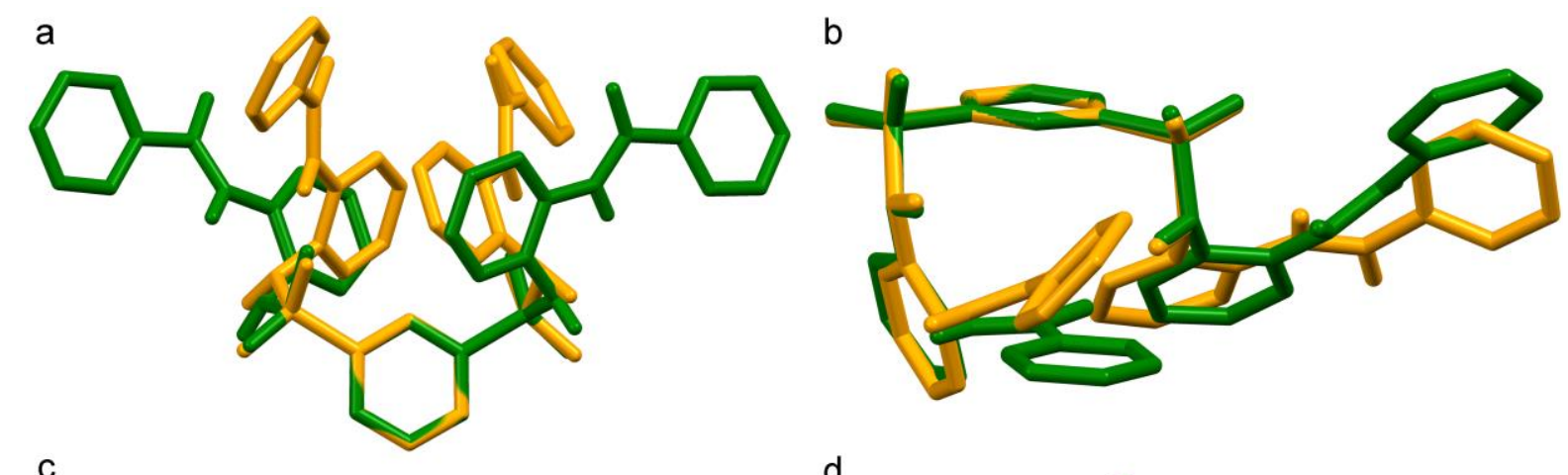

C

d
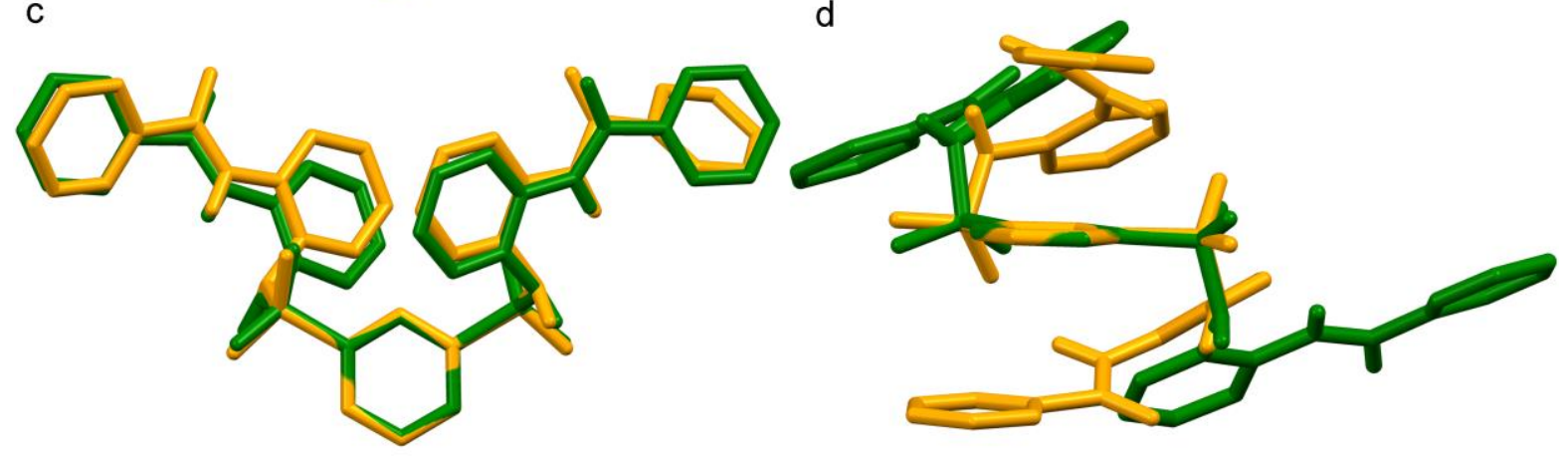

Figure 4. Overlay figures ${ }^{37}$ of solvate conformer 2 I and calculated conformer 2 I (a), solvate conformer 2II and calculated conformer 2II (b), solvate conformer $\mathbf{2 I}$ and an open conformer in the optimized dimeric pair of 2I (c), and solvate conformer 2II and calculated conformer 2III (d). Crystal structure data and calculated structures are shown in green and yellow, respectively. Non-amide/sulfonamide hydrogen atoms have been removed for clarity.

The energies of the model systems 2 I and 2II can also be compared for insight. If only intramolecular steric hindrance is considered, the conformation of $\mathbf{2 I}$ would be expected to be more favorable because of smaller repulsion between the bulky side chains. However, the calculations indicate that conformer $\mathbf{2 I I}$ is lower in energy, though only by approximately $7-11$ $\mathrm{kJ} \mathrm{mol}^{-1}$, depending on whether the calculations were conducted in the gas phase or using a solvent model. The energy difference between the two conformers can be attributed to the strong intramolecular hydrogen bond in 2II. It is also possible to compare the energy of the "tailing" 
monomer from the optimized dimeric pair of $\mathbf{2 I}$, denoted $\mathbf{2} \mathbf{I}^{*}$, with the optimized conformer $\mathbf{2} \mathbf{I I}$ as both of these structures are very close to the geometries observed in the solid state (Figure 4). This comparison reveals that $\mathbf{2 I} *$ is higher in energy than $\mathbf{2 I I}$ by $48 \mathrm{~kJ} \mathrm{~mol}^{-1}$ (approximately 35 $\mathrm{kJ} \mathrm{mol}^{-1}$ for the solvated system), which further supports the notion that intermolecular interactions contribute much more to the stability of $\mathbf{2 I}$ in the solid state than they do in the case of 2II. Consequently, there seems to be an energetic preference towards structure $\mathbf{2 I I}$ in the gas phase and in solution which is then compensated by the external hydrogen bonding network in the solid state, giving 2I and 2II nearly equal energies as implied by the crystallization experiments. Unfortunately, the presence of severely disordered (and different) solvent molecules in the unit cells of solvates 2I and 2II prevents meaningful comparisons using computational energies based on unit cell data.

The potential energy surface of $\mathbf{2}$ is obviously complex with many different possibilities for the relative orientation of the side chains along with different secondary bonding interactions. An exhaustive search through all alternatives is beyond the scope of the present work. However, it was considered to be of interest to scan through some possible conformations, which would maximize the intramolecular hydrogen bonding and therefore the folding of $\mathbf{2}$. This led to the identification of the conformer 2 III (Figures $3 \mathrm{c}$ and $4 \mathrm{~d}$ ) that has two $\mathrm{N}-\mathrm{H} \cdots \mathrm{O}=\mathrm{C}(\mathrm{D} \cdots \mathrm{A} 2.714 \AA$, $<$ DHA $141.4^{\circ}$ ) and two $\mathrm{N}-\mathrm{H} \cdots \mathrm{O}=\mathrm{S}\left(\mathrm{D} \cdots \mathrm{A} 3.066 \AA\right.$, $<$ DHA $\left.157.6^{\circ}\right)$ hydrogen bonds which collectively give the molecule a symmetric S-shaped geometry. The terminal and central aromatic rings in 2III adopt a mutually parallel orientation, but the distance between the rings does not indicate any significant $\pi-\pi$ interactions.

Due to extensive intramolecular hydrogen bonding, the conformer $2 \mathrm{III}$ is $39 \mathrm{~kJ} \mathrm{~mol}^{-1}$ more stable than 2II (25 kJ mol ${ }^{-1}$ when using a solvent model). However, conformer 2 III was not 
experimentally observed in the solid state nor could its presence in solution be identified. This could potentially be because of (presumably) large energy barriers associated with the rotation of the bulky side chains to adopt such a folded structure. Additionally, the hydrogen bonding network in conformer $\mathbf{2 I I I}$ is easily perturbed by appropriate solvent molecules, which could prevent its formation altogether.

\section{Structural comparisons}

A search through the Cambridge Structural Database yielded only three sulfonamides related to 2 that contain a benzene-1,3-disulfonamide core with aromatic side chains (4-6; Figure 4). ${ }^{24,38,39}$ In $\mathbf{4}$ and $\mathbf{5}$, the $\mathrm{S}-\mathrm{N}$ bonds are oriented on the opposite sides of the central ring similarly to solvate 2I. The rigidity of the molecules and the relative position of sulfonamide groups prohibits the formation of any intramolecular $\mathrm{N}-\mathrm{H} \cdots \mathrm{O}=\mathrm{S}$ hydrogen bonds. Instead, the solid state structures of $\mathbf{4}$ and $\mathbf{5}$ exhibit intermolecular hydrogen bonds between the sulfonamide groups, which in the case of 5 results in the formation of molecular chains along the crystallographic $a$ axis. ${ }^{38}$ In the case of $\mathbf{4}$, the intermolecular hydrogen bonding network involves one of the two carbonyl oxygen atoms on the aromatic side chains in addition to the sulfonamide groups. ${ }^{24}$ Consequently, the conformation adopted by $\mathbf{4}$ and $\mathbf{5}$ is likely to be caused by favorable intermolecular hydrogen bonding and by steric hindrance associated with the bulky side chains. DFT calculations conducted for a single molecule of $\mathbf{5}$ predict a conformer with both aromatic side chains on the same side of the central ring to be lower in energy by $15 \mathrm{~kJ} \mathrm{~mol}^{-1}$ (see ESI Figure S4). This supports the view that the conformation adopted by $\mathbf{5}$ in the solid state is strongly influenced by favorable intermolecular hydrogen bonding interactions. 

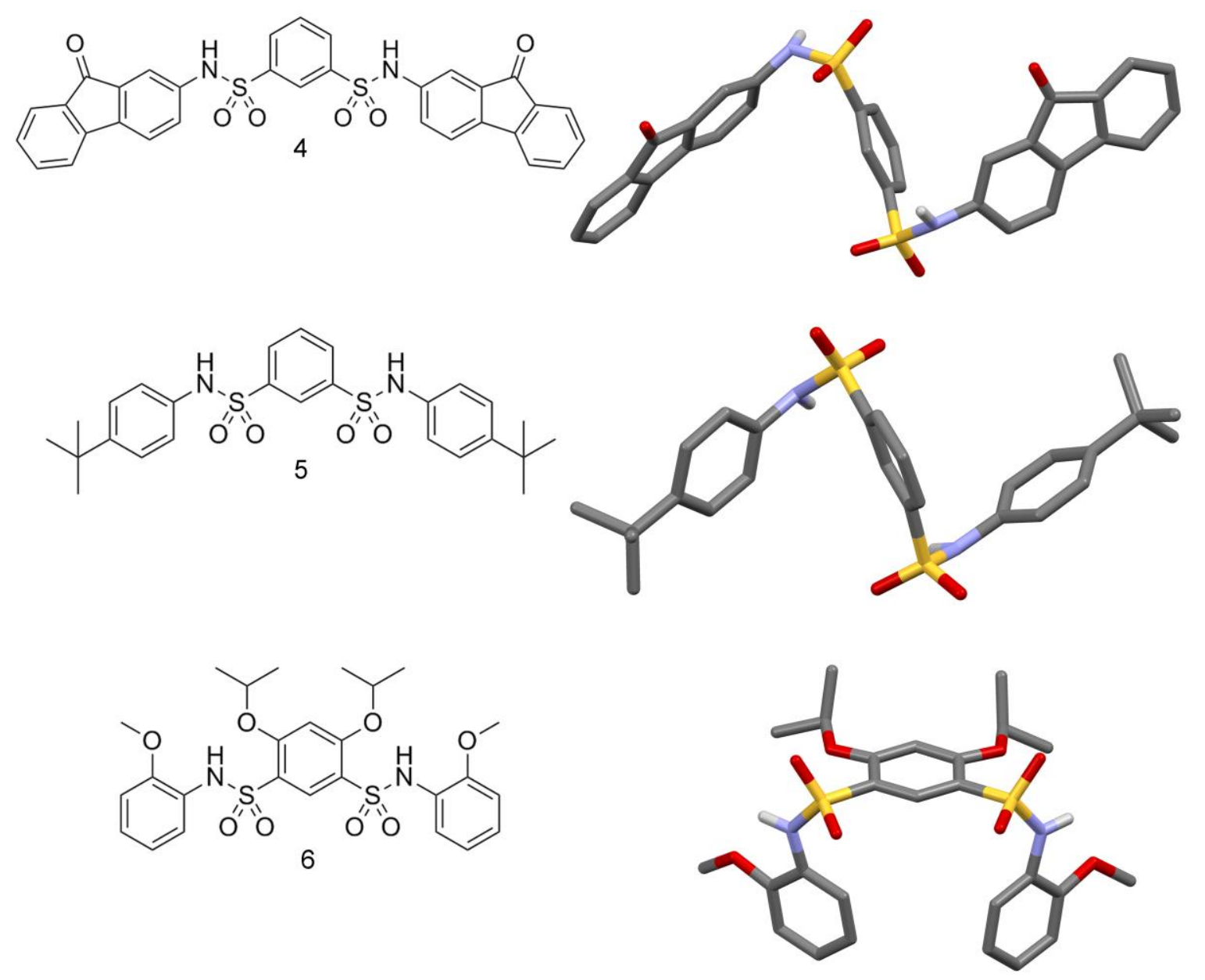

Figure 5. Molecular structures and conformations of disulfonamides $4-\mathbf{6}^{24,38,39}$ Nonamide/sulfonamide hydrogen atoms, solvent molecules and the disorder of the tert-butyl substituents have been removed for clarity.

The conformation of compound $\mathbf{6}$ is similar to that of $\mathbf{2}$ in solvate 2II. In this case, however, there is no intramolecular hydrogen bond explaining the orientation of the aromatic side chains on the same side of the central ring, but the conformation can be rationalized by the bulky isopropyl substituents, which direct the sulfonamide groups on the same side of the central ring. DFT calculations conducted for the two possible conformers of 6 indicate a small, $10 \mathrm{~kJ} \mathrm{~mol}^{-1}$, energetic preference for the geometry observed in the solid state. In agreement with these 
structural features, it has been shown that the alkoxy substituted diarylsulfonamide moiety in $\mathbf{6}$ is a convergent structural unit that can be used to build larger macrocyclic oligosulfonamides with predictable conformations. ${ }^{38}$

The Cambridge Structural Database was also searched for molecules similar to the folded conformer 2III that was identified by calculations. A closely related conformer has been reported for compound 7 with a 4-methylphenol-2,5-disulfonamide core (Figure 5) ${ }^{40}$ The conformational flexibility of 7 can be ascribed to the methylene linkers between the sulfonamide groups and the terminal pyridyl rings, which, in the absence of significant steric strain, allow the molecule to adopt a folded S-shaped geometry in the solid state. Further stabilization for 7 is provided by intermolecular $\mathrm{N}-\mathrm{H} \cdots \mathrm{N}$ and $\mathrm{O}-\mathrm{H} \cdots \mathrm{N}$ hydrogen bonds and offset $\pi-\pi$ stacking interactions that organize the molecules into parallel columns along the crystallographic $a$-axis. DFT calculations for molecule 7 reproduce well the S-shaped geometry observed in the solid state (see ESI for details). This strongly suggests that the folded conformation of the molecule is not just a result of packing effects and favorable intermolecular interactions in the solid state.
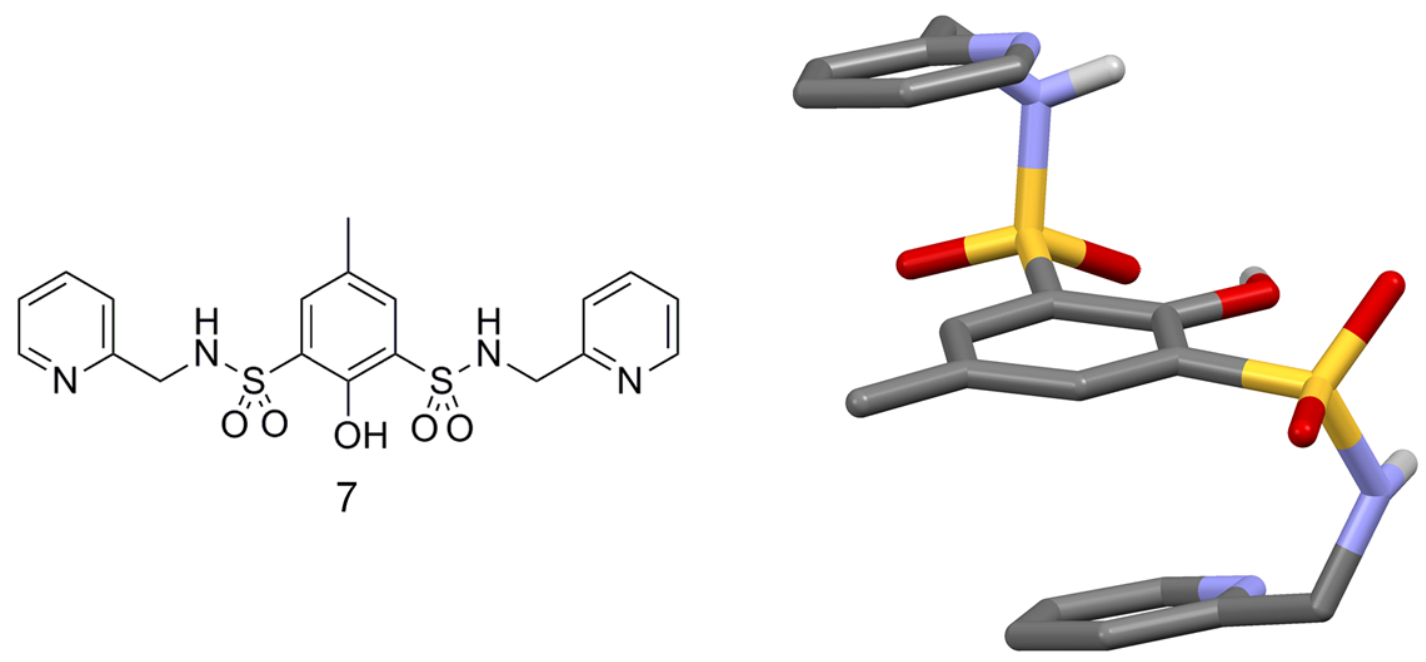

Figure 6. Molecular structure and conformation of disulfonamide 7 related to 2 IIII. ${ }^{40}$ Non-amide and non-hydroxide hydrogen atoms have been removed for clarity. 


\section{Conclusions}

The folding of a disulfonamide compound $\mathbf{2}$ was studied both experimentally and computationally, and the results were compared to data reported for closely related oligoamide and disulfonamides 3-7. Two significantly different conformers of $\mathbf{2}$ were observed in the solid state, one symmetrical and unfolded and the other unsymmetrical and loosely folded. Calculations at the density functional level of theory showed that the observed conformers are relatively close in energy, which suggests that the adaption of a specific conformer during crystal nucleation involves a delicate interplay of intra- and/or intermolecular hydrogen bonding and steric hindrance caused by the bulky side chains. The calculations also indicated a third possible conformer of 2 with multiple intramolecular hydrogen bonds, giving the molecule both an Sshaped geometry and lower energy. The reason why this conformer was not observed experimentally was tentatively attributed to the energy barriers involved in the rotation of the side chains to adopt such a folded conformation.

The results indicate that oligomers with both amide and sulfonamide groups can easily assume at least two different stable conformers without apparent environmental factors. Thus, the controlled use of sulfonamide bond as a component in foldamers is challenging and possibly requires synthetic modifications toward more flexible side chains or the use of a pyridine core. In analogous oligoamides, these changes have led to more folded structures and increased intramolecular hydrogen bonding. However, both the number of interaction sites in the sulfonamide derivative $\mathbf{2}$ and its ability to form channel structures suggest that it could potentially be used as a co-crystal host. 


\section{Acknowledgements}

B.Sc. Hélène Campos Barbosa and B.Sc. Anniina Aho are acknowledged for their help with the syntheses and crystallizations. We thank Dr. Elina Kalenius (ESI-TOF mass spectra), Laboratory Technician Elina Hautakangas (elemental analysis) and Chief Laboratory Technician Esa Haapaniemi (NMR spectroscopy). Financial support from the Academy of Finland (project 2100001911, KH and MN; projects 136929, 253907 and 272900, ISM and HMT) is gratefully acknowledged.

\section{Supporting Information}

Crystallographic data for two isomorphous preliminary structures of compound $\mathbf{2}$ ( $\mathrm{MeCN}$ and THF solvates) and notes on the crystallographic data. X-ray crystallographic information files (CIF) of solvates 2I, 2IB, 2II and 2IIB. Hydrogen bonding parameters and relevant torsion angles (all structures), a figure of solvent channels in the structure of solvate $2 \mathbf{I}$ and graphical representations of $\pi-\pi$ stacking interactions for solvates 2 I and 2II. Powder X-ray diffraction data of compound 2 (calculated and measured). ${ }^{1} \mathrm{H},{ }^{13} \mathrm{C}, \mathrm{COSY}, \mathrm{HMBC}$ and HMQC NMR spectra of 2 in DMSO- $d_{6}$, a NOESY NMR spectra in acetone- $d_{6}$ and ${ }^{1} \mathrm{H}$ NMR spectra at $30^{\circ} \mathrm{C}$ and at $-80^{\circ} \mathrm{C}$ in acetone- $d_{6}$. Optimized geometries (gas phase) of 2I, 2I dimeric pair, 2II and 2III in $x y z-$ format, energies of structures 2I, 2I*, 2II, and 2III, overlay figures of calculated and experimental structures of compounds 5-7 and optimized structure of 5. This material is available free of charge via the Internet at http://pubs.acs.org. Crystallographic information files are also available from the Cambridge Crystallographic Data Center (CCDC) upon request (http://www.ccdc.cam.ac.uk; CCDC deposition numbers 1022889-1022892). 


\section{References}

(1) Grant, D. J. W. In Polymorphism in Pharmaceutical Solids; Brittain, H. G., Ed.; Marcel Dekker, Inc., New York, USA, 1999, pp 1-34.

(2) Gellman, S. H. Acc. Chem. Res., 1998, 31, 173-180.

(3) Hill, D. J.; Mio, M. J.; Prince, R. B.; Hughes, T. S.; Moore, J. S. Chem. Rev., 2001, 101, 3893-4011.

(4) Guichard G.; Huc, I. Chem. Commun., 2011, 47, 5933-5941.

(5) Becerril, J.; Rodriguez, J. M.; Saraogi, I.; Hamilton, A. D. in Foldamers: Structure, Properties, and Applications; Hecht, S.; Huc, I.; Eds.; Wiley-VCH Verlag GmbH \& Co. KGaA, Weinheim, Germany, 2007.

(6) Zhang, D.-W.; Zhao, X.; Hou, J.-L.; Li, Z.-T. Chem. Rev., 2012, 112, 5271-5316.

(7) Huc, I. Eur. J. Org. Chem., 2004, 17-29.

(8) Monnee, M. C. F.; Marjne, M. F.; Brouwer, A. W.; Liskamp, R. M. J. Tetrahedron Lett., 2000, 41, 7991-7995. Erratum: Tetrahedron Lett., 2001, 42, 965.

(9) Ramesh, V. V. E.; Kale, S. S.; Kotmale, A. S.; Gawade, R. L.; Puranik, V. G.; Rajamonahan, P. R.; Sanjayan, G. J. Org. Lett., 2013, 15, 1504-1507.

(10) Baldauf, C.; Günther, R.; Hofmann, H.-J. J. Mol. Struct. (Theochem), 2004, 675, 19-28.

(11) Adsmond, D. A.; Grant, D. J. W. J. Pharm. Sci., 2001, 90, 2058-2077.

(12) Sanphui, P.; Sarma, B.; Nangia, A. Cryst. Growth Des., 2010, 10, 4550-4564.

(13) Terada, S.; Katagiri, K.; Masu, H.; Danjo, H.; Sei, Y.; Kawahata, M.; Tominaga, M.; Yamaguchi, K.; Azumaya, I. Cryst. Growth Des., 2012, 12, 2908-2916.

(14) Vijayadas, K. N.; Davis, H. C.; Kotmale, A. S.; Gawade, R. L.; Puranik, V. G.; Rajamohanan, P. R.; Sanjayan, G. J. Chem. Commun., 2012, 48, 9747-9749.

(15) Caira, M. R. Mol. Pharmaceutics, 2007, 4, 310-316.

(16) Wainwright, M.; Kristiansen, J. E. Dyes and Pigments, 2011, 88, 231-234.

(17) Supuran, C. T.; Scozzafava, A. Med. Res. Rev., 2003, 23, 535-558.

(18) Maren, T. H. Annu. Rev. Pharmacol. Toxicol., 1976, 16, 309-327.

(19) Nakashima, K.; Murahashi, M.; Yuasa, H.; Ina, M.; Tada, N.; Itoh, A.; Hirashima, S.-I.; Koseki, Y.; Miura, T. Molecules, 2013, 18, 14529-14542.

(20) Yang, H.; Carter, R. G. Synlett., 2010, 2827-2838. 
(21) Suhonen, A.; Nauha, E.; Salorinne, K.; Helttunen K.; Nissinen, M. CrystEngComm, 2012, 14, 7398-7407.

(22) Kortelainen, M.; Suhonen, A.; Hamza, A.; Pápai, I.; Nauha, E.; Yliniemelä-Sipari, S.; Nissinen M.; Pihko, P. M. Chem. Eur. J., http://dx.doi.org/10.1002/chem.201406521.

(23) Bao, X.; Zhou, Y. Sens. Actuators B, 2010, 147, 434-441.

(24) Koivunen, J. T.; Nissinen, L.; Käpylä, J.; Jokinen, J.; Pihlavisto, M.; Marjamäki, A.; Heino, J.; Huuskonen, J.; Pentikäinen, O. T. J. Am. Chem. Soc., 2011, 133, 14558-14561.

(25) Sheldrick, G. M. Acta Crystallogr., A: Found. Crystallogr., 2008, 64, 112-122.

(26) Otwinowski, Z.; Borek, D.; Majewski, W.; Minor, W. Acta Crystallogr., Sect. A: Found. Crystallogr., 2003, 59, 228-234.

(27) van der Sluis, P.; Spek, A. L. Acta Crystallogr., Sect. A: Found. Crystallogr., 1990, 46, 194-201.

(28) Spek, A. L. Acta Crystallogr., Sect. D:Biol. Cryst., 2009, 65, 148-155.

(29) Farrugia, L. J. J. Appl. Crystallogr., 1999, 32, 837-838.

(30) Etter, M. C.; MacDonald, J. C.; Bernstein, J. Acta Crystallogr., Sect B: Struct. Sci., 1990, $46,256-262$.

(31) Bernstein, J.; Davis, R. E.; Shimoni L.; Chung, N.-L. Angew. Chem., Int. Ed. Engl., 1995, $34,1555-1573$.

(32) Gaussian 09, Revision D.01, Frisch, M. J.; Trucks, G. W.; Schlegel, H. B.; Scuseria, G. E.; Robb, M. A.; Cheeseman, J. R.; Scalmani, G.; Barone, V.; Mennucci, B.; Petersson, G. A.; Nakatsuji, H.; Caricato, M.; Li, X.; Hratchian, H. P.; Izmaylov, A. F.; Bloino, J.; Zheng, G.; Sonnenberg, J. L.; Hada, M.; Ehara, M.; Toyota, K.; Fukuda, R.; Hasegawa, J.; Ishida, M.; Nakajima, T.; Honda, Y.; Kitao, O.; Nakai, H.; Vreven, T.; Montgomery, J. A., Jr.; Peralta, J. E.; Ogliaro, F.; Bearpark, M.; Heyd, J. J.; Brothers, E.; Kudin, K. N.; Staroverov, V. N.; Kobayashi, R.; Normand, J.; Raghavachari, K.; Rendell, A.; Burant, J. C.; Iyengar, S. S.; Tomasi, J.; Cossi, M.; Rega, N.; Millam, M. J.; Klene, M.; Knox, J. E.; Cross, J. B.; Bakken, V.; Adamo, C.; Jaramillo, J.; Gomperts, R.; Stratmann, R. E.; Yazyev, O.; Austin, A. J.; Cammi, R.; Pomelli, C.; Ochterski, J. W.; Martin, R. L.; Morokuma, K.; Zakrzewski, V. G.; Voth, G. A.; Salvador, P.; Dannenberg, J. J.; 
Dapprich, S.; Daniels, A. D.; Farkas, Ö.; Foresman, J. B.; Ortiz, J. V.; Cioslowski, J.; Fox, D. J. Gaussian, Inc., Wallingford CT, 2009.

(33) Chai, J.-D.; Head-Gordon, H. Phys. Chem. Chem. Phys., 2008, 10, 6615-6620.

(34) Weigend, F.; Ahlrichs, R. Phys. Chem. Chem. Phys., 2005, 7, 3297-3305.

(35) Tomasi, J.; Mennucci, B.; Cammi, R. Chem. Rev., 2005, 105, 2999-3093.

(36) Marcus, Y. Chem. Soc. Rev., 1993, 22, 409-416.

(37) Overlay figures were drawn with Mercury CSD 3.5.1. Macrae, C. F.; Bruno, I. J.; Chisholm, J. A.; Edgington, P. R.; McCabe, P.; Pidcock, E.; Rodriguez-Monge, L.; Taylor, R.; van de Streek J.; Wood, P. A.; J. Appl. Cryst., 2008, 41, 466-470.

(38) Eagle, C. T.; Kavallieratos, K.; Bryan, J. C. J. Chem. Crystallogr., 2002, 32, 165-170.

(39) He, L.; An, Y.; Yuan, L.; Feng, W.; Li, M.; Zhang, D.; Yamato, K.; Zheng, C.; Zeng, X. C.; Gong, B. Proc. Natl. Acad. Sci., 2006, 103, 10850-10855.

(40) Sundberg, J.; Witt, H.; Cameron, L.; Håkansson, M.; Bendix, J.; McKenzie, C. J. Inorg. Chem., 2014, 53, 2873-2882. 